\title{
Assessment of the Health-Promoting Behaviors of Hospitalized Patients with Non-Communicable Diseases During the Second Wave of COVID-19
}

\author{
Vachira Posai (D) \\ Wanich Suksatan (iD ${ }^{2}$ \\ Bovornpot Choompunuch ${ }^{3}$ \\ Apinya Koontalay (iD ${ }^{4}$ \\ Jatuporn Ounprasertsuk ${ }^{5}$ \\ Jonaid M Sadang ${ }^{6}$ \\ 'Nursing Department, \\ Sunpasitthiprasong Hospital, Ubon \\ Ratchathani, Thailand; ${ }^{2}$ Faculty of \\ Nursing, HRH Princess Chulabhorn \\ College of Medical Science, Chulabhorn \\ Royal Academy, Bangkok, Thailand; \\ ${ }^{3}$ Faculty of Education, Mahasarakham \\ University, Mahasarakham, Thailand; \\ ${ }^{4}$ Independent Researcher, Melbourne, \\ VIC, Australia; ${ }^{5}$ College of Allied Health \\ Sciences, Suan Sunandha Rajabhat \\ University, Bangkok, Samut Songkram \\ Province, Thailand; ${ }^{6}$ College of Health \\ Sciences, Mindanao State University- \\ Marawi, Marawi, Philippines
}

Background: The coronavirus disease 2019 (COVID-19) pandemic has affected the healthrelated behaviors of patients with non-communicable diseases (NCDs). Thus, the factors predicting the health-promoting behaviors (HPBs) of hospitalized patients with NCDs during the second wave of COVID-19 should be examined.

Objective: The aims of this study were to determine the relationships among the patients' characteristics, perceived self-efficacy, social support, perception of the benefits of and barriers, and HPBs, and to determine the predictive factors of HPBs among hospitalized patients with NCDs during the second wave of COVID-19.

Patients and Methods: The study had a cross-sectional predictive correlational design and included 250 patients with NCDs 18 years of age or older hospitalized in a tertiary hospital in Thailand. Descriptive statistics, the chi-square test, the Pearson's correlation coefficient, and stepwise multiple linear regression were used for data analysis.

Results: Most of the participants had a cardiovascular disease (34.0\%). Followed by diabetes (28.8\%), cancer $(11.2 \%)$, hypertension $(10.0 \%)$, heart disease $(9.6 \%)$, or chronic obstructive pulmonary disease $(6.4 \%)$ and had a moderate level of overall HPBs $(\mathrm{M}=106.09$; $\mathrm{SD}=4.66)$. Among the six components of the HPBs, the participants achieved the moderate levels in nutrition, interpersonal relations, spiritual growth, and stress management, and low levels in physical-activity and health responsibility. The patients' perception of the benefits and barriers to the adoption of HPBs and perceived self-efficacy and social support were able to predict their HPBs, accounting for approximately $38.0 \%$ of the variance of such behaviors.

Conclusion: On the basis of our study's results, we suggest that researchers, multidisciplinary teams, the government, and policymakers establish effective interventions, guidelines, and policies for the development of HPBs to prevent and control the spread of COVID-19 particularly among patients with NCDs, and to improve their capacity for high-quality and continuing self-care.

Keywords: predictive factors, health-promoting behaviors, non-communicable diseases, NCDs, hospitalized patients, COVID-19

\section{Introduction}

The world is currently facing a great health crisis due to the second wave of coronavirus disease 2019 (COVID-19). ${ }^{1,2}$ Due to the virulence and mutations of the virus causing such disease (severe acute respiratory syndrome coronavirus 2 ), the number of human infections is continuing to increase, and the pathogenesis is more severe worldwide than in the first wave. ${ }^{3}$ Worldometers ${ }^{4}$ reported that as of July 11,2021 , there have been 
187,632,756 cases of COVID-19 infection and 4,049,071 COVID-19 deaths. The World Health Organization also reports the new cases of infection and deaths around the world, and the data show that COVID-19 affects all age groups and especially people who have high health risks or a weak immune system. ${ }^{2}$ Most of the patients often develop severe symptoms leading to death, including pregnant women, children aged 6 months to 2 years, older adults, disabled people, and thalassemia or immunocompromised patients. ${ }^{5,6}$ In addition, obese people with a body mass index (BMI) of $35 \mathrm{~kg} / \mathrm{m}^{2}$ and people with chronic diseases, particularly non-communicable diseases (NCDs), are also especially vulnerable to the disease. ${ }^{7-9}$

NCDs are the most important public health problems and the leading cause of death, rehospitalization, and care expenditure. ${ }^{10,11}$ The number of deaths from NCDs worldwide increased from 38 million in 2012 to 41 million in 2016 ( $71 \%$ of the total deaths worldwide), with cardiovascular disease (17.9 million, 44\%), cancer (9.0 million, 22\%), chronic respiratory diseases (3.8 million, $9 \%$ ), and diabetes (1.6 million, 4\%) causing the most deaths. ${ }^{12}$ Annually, 15 million people with NCDs within the age range 30-69 years around the world prematurely die, with the high death rates in such population in different countries severely affecting such countries' socioeconomic development. ${ }^{11}$ In Thailand, NCDs such as cardiovascular diseases, hypertension, diabetes, cancers, and chronic respiratory diseases are among the leading causes of morbidity and mortality, ${ }^{13}$ and the continuing rise in the number of people with NCDs, particularly older adults, is concerning. ${ }^{14}$

The impact of the COVID-19 pandemic on NCDs is multifaceted. Several countries, including Thailand, have implemented restrictive measures during the pandemic, such as lockdowns, social distancing, and travel restrictions, to decrease the spread of COVID-19, and this has adversely affected particularly the people with NCDs by limiting their ability to secure healthy foods and supplements, to engage in outdoor physical activities, and to obtain medical care or access health services. ${ }^{1,11}$ Evidence obtained since the start of the COVID-19 pandemic suggests that quarantine and physical distancing can lead to poor self-management of patients with NCDs and to health risk factors such as lack of physical activity, food insecurity or unhealthy consumption, harmful use of alcohol, and tobacco use. ${ }^{15}$ In addition, without adequate and proper management of NCDs, the chronic conditions can worsen due to the stress resulting from restrictions, insecure economic situation, and changes in the new normal of health-related behaviors during the pandemic. $^{16}$

NCDs can be prevented and controlled if the patients carry out regular and ongoing self-care. When patients with NCDs have appropriate self-care and healthpromoting behaviors, they can help reduce the severity of the disease and improve their quality of life. Although several researchers have assessed health-promoting behaviors, most of the previous studies focused only on the health-promoting behaviors (HPBs) of patients with NCDs living in communities. ${ }^{13,14,17}$ Hospitalized patients with NCDs during the second wave of COVID-19 face great challenges because before their hospital discharge, they need to prepare to take care of themselves at home, without support from multidisciplinary healthcare teams.

The objectives of this study were to determine the relationships among the characteristics, perceived selfefficacy, social support, perceived benefits of and barriers to the adoption of health-promoting behaviors, and HPBs of hospitalized patients with NCDs during the second wave of COVID-19, and to investigate the ability of the independent variables to predict such patients' healthpromoting behaviors. The results of the study can be used as a guideline for discharge planning interventions that are comprehensively consistent with the needs of patients with NCDs. When patients with NCDs have appropriate health behaviors and are able to integrate selfcare activities in their daily routine, the severity of their disease and its complications, their disabilities, and their rehospitalization rate will be reduced, and their quality of life at home during the COVID-19 pandemic will improve.

\section{Materials and Methods Research Design and Sampling}

This cross-sectional predictive correlational study was conducted in a tertiary hospital in Thailand from March 4 to April 30, 2021. It involved patients who had been diagnosed with an NCD by a physician and who were hospitalized in the medical ward of a tertiary hospital in Thailand during the second wave of COVID-19.

Included in the study were as follows: (1) both males and females aged 18 years of age or over; (2) patients with one or more NCDs (eg, diabetes, hypertension, cardiovascular and heart disease, chronic obstructive pulmonary disease, cancer); (3) patients attending the medical wards of Sunpasitthiprasong Hospital, Ubon Ratchathani Province, Thailand; and (4) patients who were able to communicate 
in and understand Thai. Patients who had other visual/auditory/sensory abnormality, had been diagnosed with a neuropsychiatric disorder (on the basis of their medical records), and were not willing to voluntarily participate in the study were excluded from the study. The convenient sampling method was used, and the sample size was calculated using the $\mathrm{G}^{*}$ Power program. ${ }^{18,19}$ The effect size from a prior study was $0.15,{ }^{20}$ with an alpha level of 0.05 and 0.8 power. As such, we increased the number of samples by approximately $30 \%$ to anticipate the potential incomplete responses to the questionnaires. Therefore, the final sample size of this study was 250 .

\section{Research Instruments}

Six research instruments were employed in this study: (1) Perceived Benefit Scale (PBenS); (2) Perceived SelfEfficacy Scale (PSES); (3) Perceived Barrier Scale (PBarS); (4) Social Support Scale (SSS); (5) HealthPromoting Behaviors Scale (HPBS); (6) demographic questionnaire for patients with NCDs. Permission to use all these instruments in the study was obtained from their owners. The Thai versions of PBenS, PSES, PBarS, and SSS were used while HPBS was previously translated from English to Thai and was validated in the Thai context. All the questionnaires were examined for content validity by five experts on patients with NCDs. The content validity indices of PBenS, PSES, PBarS, SSS, and HPBS were $0.83,1.00,0.83,1.00$, and 1.00 , respectively.

\section{Perceived Benefit Scale (PBenS)}

PBenS was used to determine the patients' perceptions of the appropriate health-promoting behaviors and the benefit of adopting these. We developed PBenS on the basis of the work by Bunplaeng, ${ }^{21}$ it had 38 items with a 4-point scale, where $4=$ strongly, $3=$ agree, $2=$ disagree, and $1=$ strongly disagree (1). The scores ranged from 38 to 152 , with higher scores indicating a higher perceived benefit. The Cronbach's alpha coefficient in this study was 0.94 .

\section{Perceived Self-Efficacy Scale (PSES)}

PSES was used to assess the patients' perceptions that there were obstacles to their self-health-promoting behaviors. The researchers developed PSES on the basis of the literature review and a previous study; ${ }^{21}$ it had 28 items with a 4-point scale, where $4=$ strongly, $3=$ agree, $2=$ disagree, and $1=$ strongly disagree (1). The scores ranged from 28 to 112, with higher scores indicating higher perceived self-efficacy. The Cronbach's alpha coefficient in this study was 0.87 .

\section{Perceived Barrier Scale (PBarS)}

PBarS was used to assess the patients' confidence in their ability to consistently carry out various health-promoting behaviors. We developed PBarS on the basis of the literature review and a previous study; ${ }^{22}$ it had 30 items with a 4-point scale, where $4=$ strongly, $3=$ agree, $2=$ disagree, and $1=$ strongly disagree (1). The scores ranged from 30 to 120 , with higher scores indicating higher perceived barriers. The Cronbach's alpha coefficient in this study was 0.88 .

\section{Social Support (SSS)}

SSS was used to assess whether the patients were receiving care support from other people, such as their families, or were being encouraged by the latter to take care of their health. We developed SSS on the basis of the literature review and a previous study; ${ }^{13}$ it had 16 items with a 4-point scale, where 4 = strongly, 3 = agree, 2 = disagree, and $1=$ strongly disagree (1). The scores ranged from 16 to 64 , with higher scores indicating higher social support. The Cronbach's alpha coefficient in this study was 0.91 .

\section{Health-Promoting Behaviors Scale (HPBS)}

HPBS was used to assess the patients' health-promoting activities and whether they had made these part of their lifestyle plan or routine, which would have a beneficial effect on their health conditions. We used the HPBS Thai version developed by Seeherunwong and Suwonnaroop, ${ }^{23}$ which has 43 items with six components: (a) health responsibility (items 1-7), the mean scores are classified into three levels of frequency: $<17=$ low, $17-22=$ moderate, and $>22=$ higher health responsibility; (b) physical activity (items 814), the mean scores are classified into three levels of frequency: $<17=$ low, $17-22=$ moderate, and $>22=$ higher physical activity; (c) nutrition (items 15-22), the mean scores are classified into three levels of frequency: $<19=$ low, 19-26 $=$ moderate, and $>26=$ higher nutrition; (d) interpersonal relations (items 23-29), the mean scores are classified into three levels of frequency: $<17=$ low, 17-22 = moderate, and $>22$ = higher interpersonal relations; (e) spiritual growth (items 30-37), the mean scores are classified into three levels of frequency: $<19=$ low, 19-26 = moderate, and $>26=$ higher spiritual growth; and (f) stress management (items 38-43), the mean scores are classified into three levels of frequency: $<14=$ low, 14-19= moderate, and $>19=$ higher stress management. All the items were evaluated on the basis of a 4-point scale, where $4=$ strongly, $3=$ agree, $2=$ disagree, and $1=$ strongly disagree. The overall mean scores are 
classified into three levels of frequency: $<103=10 w, 103-$ $138=$ moderate, and $>138$ = higher health-promoting behaviors. The Cronbach's alpha coefficient in this study was 0.93 , ranging for each component from 0.76 to 0.92 .

\section{Sociodemographic Variables}

The demographic questionnaire was characterized by 11 open-ended or multiple-choice questions consisting of gender, age, weight, height, monthly income, religion, status, education level, health insurance type, perceived health condition, and type of chronic NCD. We calculated the BMI from the self-reported height and weight, as weight in kilograms divided by the square of height in meters.

\section{Data Collection}

Before the study commencement, we obtained study approval from the director of Sunphasitthiprasong Hospital, Ubon Ratchathani, and human research ethics approval from the Human Research Ethics Committee of Suppasitprasong Hospital, Ubon Ratchathani. We then explained the study objectives and procedures to the participants, and how we would protect their rights in connection to the study. After obtaining the participants' written consent to participate in the study, we explained to them how to accomplish the questionnaires and gave them an opportunity to ask questions thereafter. We then asked the participants to accomplish the questionnaires. Finally, we examined the accomplished questionnaires for completeness and correctness before conducting statistical analysis.

\section{Ethical Considerations}

The current study was endorsed by the Human Research Ethics Committee of Sanphasitthiprasong Hospital, Ubon Ratchathani (Research Project Code No. 001/64s; dated 3 March 2021). The study was conducted in accordance with the Declaration of Helsinki. As mentioned earlier, before the study commencement, we explained the study objectives and procedures to the participants in detail, and obtained their written consent to participate in the study. We made it clear to the participants that they had the right to decline participation in the study and to withdraw from the study without any consequence. The information obtained from the participants was kept confidential, and the study results are presented herein only for academic purposes.

\section{Statistical Analysis}

All the obtained data were analyzed using Statistical Package for Social Sciences version 21 (SPSS, IL, USA). The data are presented herein as the frequency, percentage, mean, standard deviation, maximum, and minimum. We used the chi-square test and Pearson's correlation coefficient to determine the relationships among the participants' characteristics, perceived self-efficacy, social support, perception of the benefits of and barriers to their adoption of health-promoting behaviors, and healthpromoting behaviors. We also used stepwise-multiple regression analysis to determine the predictive factors of the patients' health-promoting behaviors. $P$-value $<0.05$ was considered statistically significant.

\section{Results}

\section{Characteristics of the Participants}

Most of the 250 participants were female (58.0\%), and their mean age was 48.92 years (standard deviation [SD] $=$ $8.90)$, their average BMI was $27.76 \mathrm{~kg} / \mathrm{m}^{2}(\mathrm{SD}=6.51)$, their mean weight was $64.39 \mathrm{~kg}(\mathrm{SD}=14.51)$, their mean height was $152.72 \mathrm{~cm}(\mathrm{SD}=6.82)$, their average monthly income was 6001-9000 Thai Baht (46.0\%), and their most respected religion was Buddhism (94.8\%). Most of them were married $(\mathrm{n}=158 ; 63.2 \%)$, and the highest education level attained by most of them was primary school $(\mathrm{n}=$ $199 ; 79.6 \%$ ). Furthermore, $74.4 \%$ of the participants had universal health coverage (UHC), as shown in Table 1.

As shown in Figure 1, the overall health condition of both the male and female patients with NCDs was at a moderate level $(83.20 \%)$. As for the underlying disease, most of the participants had a cardiovascular disease $(34.0 \%)$ and the others had diabetes $(28.8 \%)$, cancer $(11.2 \%)$, hypertension $(10.0 \%)$, heart disease $(9.6 \%)$, and chronic obstructive pulmonary disease (COPD; $6.4 \%$ ), as shown in Figure 2.

\section{Levels of Independent Variables and Health-Promoting Behaviors of the Participants}

The overall HPBs scores of the participants were at a moderate level (mean $[\mathrm{M}]=106.09$; $\mathrm{SD}=4.66)$ in terms of components, we found that nutrition $(\mathrm{M}=23.06$; $\mathrm{SD}=$ 2.08), interpersonal relations $(\mathrm{M}=18.88 ; \mathrm{SD}=1.98)$, spiritual growth $(\mathrm{M}=21.16 ; \mathrm{SD}=2.02)$, and stress management $(\mathrm{M}=14.87 ; \mathrm{SD}=1.15)$, they were at moderate levels. As for the participants' scores for the physical-activity and health 
Table I Sociodemographic Status of the Participants

\begin{tabular}{|c|c|c|c|c|}
\hline \multicolumn{2}{|c|}{ Demographic Characteristics } & \multirow{2}{*}{$\frac{\text { Frequency }(\mathbf{N}=\mathbf{2 5 0})}{105}$} & \multirow[t]{2}{*}{ Mean \pm SD } & \multirow{2}{*}{$\begin{array}{c}\text { Percent (\%) } \\
42.0\end{array}$} \\
\hline Sex & Male & & & \\
\hline & Female & 145 & & 58.0 \\
\hline \multicolumn{2}{|l|}{ Age } & 250 & $48.92 \pm 8.90$ & \\
\hline \multicolumn{2}{|l|}{ Body weight } & 250 & $64.39 \pm|4.5|$ & \\
\hline \multicolumn{2}{|l|}{ Body height } & 250 & $152.72 \pm 6.82$ & \\
\hline \multicolumn{2}{|l|}{ BMI } & 250 & $27.76 \pm 6.51$ & \\
\hline \multirow[t]{3}{*}{ Monthly income (USD) } & $<200$ (6000 Thai Baht) & 105 & & 42.0 \\
\hline & 200-300 (600I-9000 Thai Baht) & 115 & & 46.0 \\
\hline & > 300 (9000 Thai Baht) & 30 & & 12.0 \\
\hline \multirow[t]{3}{*}{ Religion } & Buddhism & 237 & & 94.8 \\
\hline & Christianity & 8 & & 3.2 \\
\hline & Islam & 5 & & 2.0 \\
\hline \multirow[t]{4}{*}{ Marital status } & Single & 24 & & 9.6 \\
\hline & Married & 158 & & 63.2 \\
\hline & Widow & 58 & & 23.2 \\
\hline & Disclosed & 10 & & 4.0 \\
\hline \multirow[t]{3}{*}{ Education level } & Primary school or lower & 199 & & 79.6 \\
\hline & High school & 43 & & 17.2 \\
\hline & Undergraduate or higher & 8 & & 3.2 \\
\hline \multirow[t]{4}{*}{ Health insurance } & $\mathrm{UHC}$ & 186 & & 74.4 \\
\hline & Social security & 30 & & 12.0 \\
\hline & Civil servant & 28 & & 11.2 \\
\hline & Private insurance & 6 & & 2.4 \\
\hline
\end{tabular}

Abbreviations: BMI, body mass index; UHC, universal health coverage.

responsibility components of HPBs, they were at low levels $[(\mathrm{M}=11.48 ; \mathrm{SD}=2.06),(\mathrm{M}=16.64 ; \mathrm{SD}=1.34)$, respectively], as shown in Table 2.

\section{Relationships Between the Independent Variables and the Health-Promoting Behaviors of the Participants}

In our study, age was significantly positively associated with perceived self-efficacy $(\mathrm{r}=0.138 ; p<0.05)$, social support $(\mathrm{r}$ $=0.172 ; p<0.05)$, and HPBs $(\mathrm{r}=0.132 ; p<0.05)$. There was a positive correlation between the patients' perceived selfefficacy and social support $(\mathrm{r}=0.157 ; p<0.05)$. We also found that perceived benefits $(\mathrm{r}=0.440 ; p<0.001)$, perceived self-efficacy $(\mathrm{r}=0.730 ; p<0.001)$, and social support were significantly positively associated with HPBs $(\mathrm{r}=0.150 ; p<0.05)$. On the contrary, there was a negative correlation between perceived self-efficacy and the perceived benefits of adopting HPBs $(\mathrm{r}=-0.181 ; p<0.001)$. In addition, perceived barriers was significantly negatively associated with HBPs in patients with NCDs during COVID-19 pandemic $(\mathrm{r}=-0.870 ; p<0.001)$, as shown in Table 3 .

\section{Predictors of Health-Promoting Behaviors in Patients with NCDs}

In this study, the following results were obtained regarding the ability of the four independent variables (perceived self- 


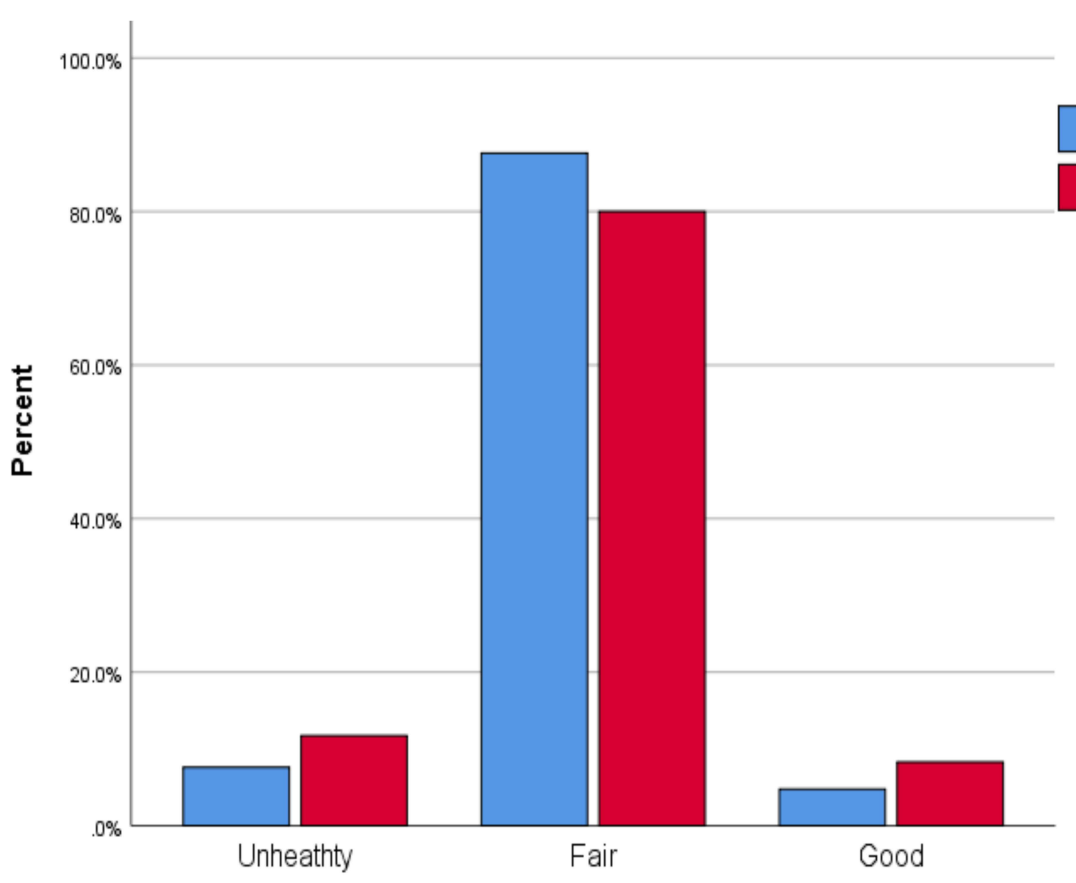

Figure I Distribution of health status among hospitalized patients with NCDs.

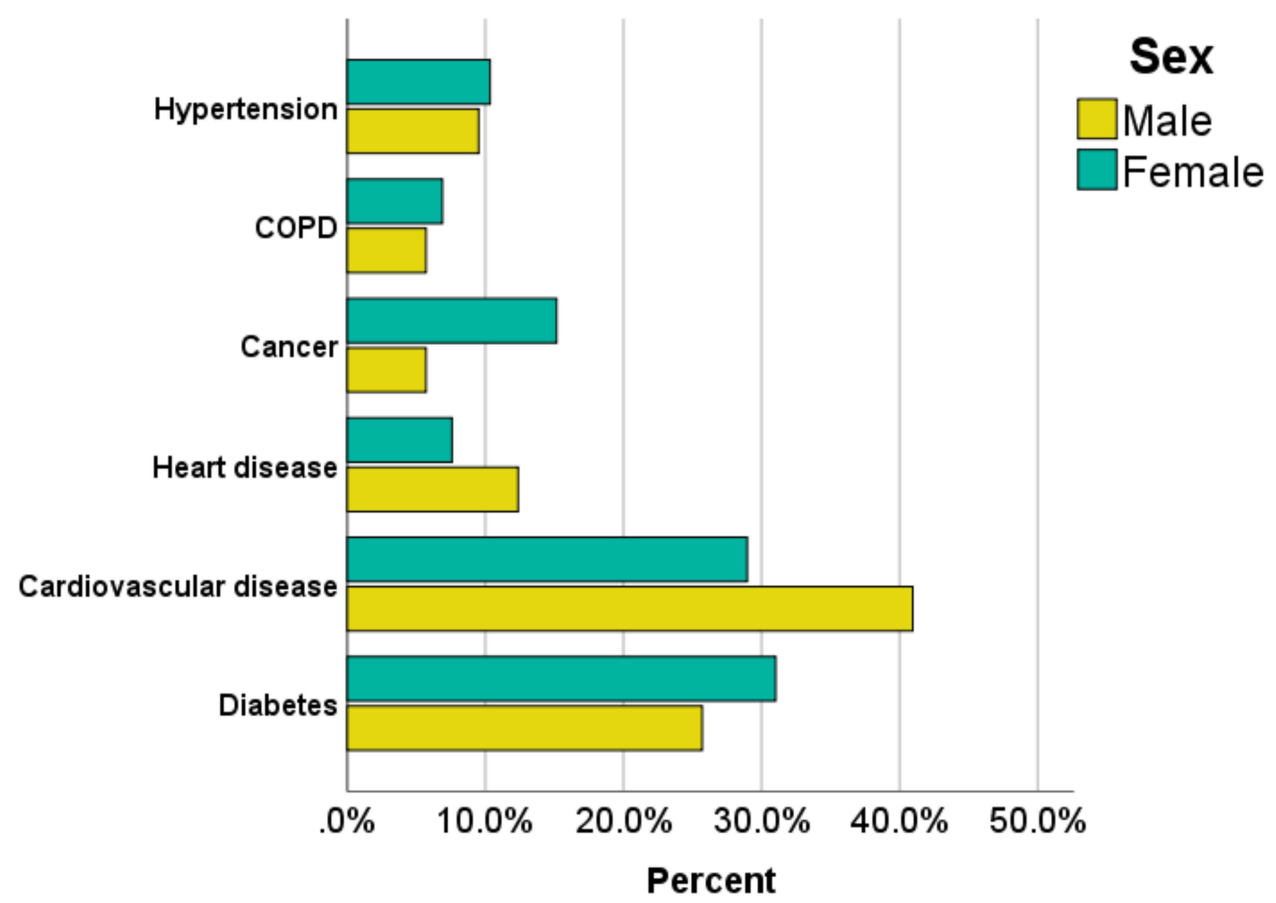

Figure 2 Distribution of underlying diseases among hospitalized patients with NCDs.

efficacy, social support, perceived benefits, and perceived barriers to the adoption of health-promoting behaviors) to predict the HPBs of patients with NCDs: perceived benefits of adopting HPBs, perceived barriers to the adoption of HBPs, perceived self-efficacy, and social support. The prediction model was statistically significant $(F(4,250)=$
Sex

Male

Female 
Table 2 Mean, Standard Deviation, and Level of Health-Promoting Behaviors

\begin{tabular}{|c|c|c|c|c|}
\hline \multirow[t]{3}{*}{ Variable } & \multirow[t]{3}{*}{ Mean \pm SD } & \multicolumn{3}{|c|}{ Levels of Variables } \\
\hline & & High & Moderate & Low \\
\hline & & n (\%) & n (\%) & n (\%) \\
\hline Health-Promoting Behaviors (HPBs) & $106.09 \pm 4.66$ & $9(3.6)$ & $24 I(96.4)$ & $0(0.0)$ \\
\hline Health Responsibility & $16.64 \pm 1.34$ & $0(0.0)$ & $138(55.2)$ & I I 2 (44.8) \\
\hline Physical Activity & $11.48 \pm 2.06$ & $0(0.0)$ & $4(1.6)$ & $246(98.4)$ \\
\hline Nutrition & $23.06 \pm 2.08$ & $43(17.2)$ & $199(79.6)$ & $8(3.2)$ \\
\hline Interpersonal Relations & $18.88 \pm 1.98$ & $9(3.6)$ & $213(85.2)$ & $28(11.2)$ \\
\hline Spiritual Growth & $21.16 \pm 2.02$ & $3(1.2)$ & $203(8 I .2)$ & $44(17.6)$ \\
\hline Stress Management & $14.87 \pm 1.15$ & $0(0.0)$ & $161(64.4)$ & $89(35.6)$ \\
\hline
\end{tabular}

Table 3 Correlation Matrix of Health-Promoting Behaviors

\begin{tabular}{|l|c|c|c|c|c|c|}
\hline Variable & $\mathbf{I}$ & $\mathbf{2}$ & $\mathbf{3}$ & $\mathbf{4}$ & $\mathbf{5}$ & $\mathbf{6}$ \\
\hline I. Age & $\mathrm{I}$ & & & & & \\
2. Perceived Benefit & -0.030 & $\mathrm{I}$ & & & \\
3. Perceived Self-Efficacy & $0.138^{*}$ & $-0.18 \mathrm{I}^{* *}$ & $\mathrm{I}$ & & \\
4. Perceived Barriers & 0.560 & 0.740 & -0.120 & 1 & \\
5. Social Support & $0.172^{*}$ & -0.112 & $0.157^{*}$ & 0.180 & 1 \\
6. Health-Promoting Behaviors & $0.132^{*}$ & $0.440^{* *}$ & $0.730^{* *}$ & $-0.870^{* *}$ & $0.150^{*}$ & \\
\hline
\end{tabular}

Notes: ${ }^{*} p$-value $<0.05 ;{ }^{* *} p$-value $<0.01$.

adjusting for perceived self-efficacy, social support, and perceived benefits $(\beta=-0.090, p<0.001)$. Moreover, perceived self-efficacy was a predictor of HPBs when adjusting for perceived barriers, social support, and perceived benefits $(\beta=0.063, p<0.001)$. In addition, social support was a predictor of HPBs when adjusting for perceived barriers, perceived self-efficacy, and perceived benefits $(\beta=0.147$, $p<0.001$ ), as shown in Table 4 .

\section{Discussion}

With regard to the relationships among the participants' characteristics, perceived self-efficacy, social support, perceived benefits of and barriers to the adoption of healthpromoting behaviors, and HPBs and the factors that could predict HPBs among hospitalized patients with NCDs during the second wave of COVID-19, we found that the four independent variables in this study could predict the HPBs of patients with NCDs, accounting for approximately $38.0 \%$ of the variance of such behaviors.

It was found in this study that the best predictor of the HPBs of patients with NCDs is social support. According to House et $\mathrm{al}^{24}$ social support can help patients express their distress and frustration and feel valued and important, and inevitably affects their ability to take care of themselves and have better health-promoting behaviors. The findings of this study are consistent with that of Yoowattana et al, ${ }^{25}$ and of Suksatan and Ounprasertsuk, ${ }^{13}$ that social support influenced the self-care behavior of the chronically ill elderly people in the central region of Thailand $(\beta=0.376, p<0.001$ and $\beta=0.408, p<0.001$,

Table 4 Regression of Individual Health-Promoting Behaviors

\begin{tabular}{|l|c|c|c|c|c|c|}
\hline Variable & B & SE(b) & $\boldsymbol{\beta}$ & $\mathbf{t}$ & $\mathbf{P}$ value & $\mathbf{9 5 \%} \mathbf{C l}$ \\
\hline Constant Value & $\mathrm{I} 18.94$ & 11.93 & & 9.96 & $<0.00 I^{*}$ & $95.44,142.45$ \\
Perceived Benefit & 0.084 & 0.069 & 0.079 & 1.225 & $<0.00 I^{*}$ & $-0.219,0.05 \mathrm{I}$ \\
Perceived Barriers & -0.122 & 0.086 & -0.090 & -1.428 & $<0.00 I^{*}$ & $-0.046,0.29 \mathrm{I}$ \\
Perceived Self-Efficacy & 0.064 & 0.065 & 0.063 & 0.085 & $<0.00 I^{*}$ & $-0.191,0.064$ \\
Social Support & 0.216 & 0.093 & 0.147 & 2.314 & $<0.00 I^{*}$ & $-0.399,-0.032$ \\
\hline
\end{tabular}

Notes: $R=0.395 ;$ adjusted $R^{2}=0.380 ; S E=4.061 ; F=2.424 ;{ }^{*} p$-value $<0.001$. 
respectively). Similar to our results, the perception of social support by elderly patients living in a community correlate with and influence their self-care $(\beta=0.45 ; p<$ $0.014) .{ }^{26}$ On the basis of our study's results, we suggest that social support from healthcare providers and families is essential for patients with NCDs during the current COVID-19 pandemic as it may be an important contributor to behavior change in such patients, who have become inactive due to the challenges they have been facing in terms of motivation to adopt health-promoting behaviors.

Second, perception of the barriers to the adoption of HPBs was found to be another significant predictor of HPBs among hospitalized patients with NCDs during the second wave of COVID-19. This can be explained by the fact that the deteriorating physical conditions of patients with a chronic illness may hinder such patients' performance of different activities. In addition, due to the economic crisis during the pandemic, many people with chronic NCDs have lower incomes because they work less but still have to obtain treatment for their disease and stay in the hospital more often, which constitutes an obstacle to their adoption of health-promoting behaviors. A previous study demonstrated that the barriers to the adoption of HPBs perceived by older adults with hypertension in Indonesia influenced their $\operatorname{HPBs}(\beta=-0.129 ; p=$ $0.001) .{ }^{27}$ Similarly, Rasamejam et $a{ }^{28}$ found that the barriers to the adoption of HPBs perceived by Thai Muslims with hypertension influenced their HPBs $(\beta=$ $-1.61 ; p<0.001)$. Bunthan et al, ${ }^{17}$ also found that perceived barriers to the adoption of HPBs prevented older adults in Thailand to adopt HPBs to protect themselves from COVID-19 infection $(\beta=-189 ; p=0.002)$. Conversely, a previous study showed that perceived barriers to the adoption of HPBs did not significantly predict the preventive health behavior of wearing a facemask among Chinese adults to protect themselves from acquiring severe acute respiratory syndrome. However, the perceived barriers to the adoption of HPBs are important and have always played a significant role in determining patients' health-related behaviors.

Third, perceived self-efficacy significantly predicted HPBs among hospitalized patients with NCDs. This can be explained by the health promotion model: when a person has good understanding and self-efficacy, he or she will be motivated to carry out good behavior. ${ }^{29}$ Our study was also in accord with the theory of self-efficacy, ${ }^{30}$ which describes perceived self-efficacy as critical in motivating individuals to carry out certain behaviors, including health-promoting ones, to attain worthwhile goals. This result of our study is consistent with that of another study ${ }^{27}$ that perceived self-efficacy influenced the HPBs of older Indonesian adults with hypertension $(\beta=$ $0.321 ; p<0.000$ ), and with the result of the study by Bunthan et $\mathrm{al},{ }^{17}$ that perceived self-efficacy influenced the HPBs of older adults for the prevention of COVID-19 infection ( $\beta=$ $0.313 ; p=0.000)$. Overall, perceived self-efficacy was found to be an essential factor required to promote HPBs in patients with NCDs.

Finally, we found that the perceived benefits of adopting HPBs influenced the HPBs of hospitalized patients with NCDs during the second wave of COVID-19. This can be explained by health promotion model: when a person perceives the benefits of adopting health-promoting activities or anticipates the benefits that other people will receive from his or her adoption of such, it will motivate him or her to perform such behaviors. ${ }^{29}$ The benefits that hospitalized patients with NCDs can be obtain from adopting HPBs are greater knowledge and understanding of the nature of one's disease, self-care, and health prevention during hospital stay. Patients who are getting better can be discharged from the hospital and go home and take care of themselves without the support received from healthcare providers during hospitalization. This result of the current study is consistent with that of Lim et al, ${ }^{31}$ regarding the perceived benefits of adopting HPBs of the early elderly in South Korea living in rural and urban communities $(\beta=0.738$; $p=0.000$ and $\beta=0.336, p=0.000$, respectively). Suksatan ${ }^{22}$ also found that the perceived benefits of adopting HPBs influenced the HPBs of people at risk of hypertension in a rural Thai community ( $\beta=0.402 ; p<0.001)$. Additionally, perceived self-efficacy is a significant factor influencing HPBs and can predict the health outcomes of hospitalization and the quality of life of patients with NCDs (eg, diabetes, ${ }^{32}$ hypertension, ${ }^{33}$ heart failure, ${ }^{34}$ and $\mathrm{COPD}^{35}$ ).

The main strength of this study was its originality as it was the first study to predict the factors influencing the HPBs of hospitalized patients with NCDs during the second wave of COVID-19 in a tertiary hospital in Thailand. Moreover, we collected the study data directly from patients with NCDs, which may have better reflected the real situation of such patients, especially during the current pandemic. The study also showed important predictors of HPBs in patients with NCDs: perceived benefits of and barriers to the adoption of health-promoting behaviors, perceived self-efficacy, and social support. In addition, our study showed significant focus areas for the implications of our study findings: integrating our study findings with health policymaking, with the individual performance of health-promoting behaviors, 
health outcomes, and developing comprehensive interventions particularly in the transition care period through formal collaboration between the hospital and the home in the care of patients with NCDs.

The current study, however, had some limitations. First, the participants were patients with NCDs hospitalized in only one tertiary hospital in Thailand. This can limit the generalizability of our study's findings to other patients with NCDs in a different setting. Second, as regards the nature of the sample, which was obtained using the convenient sampling method, the non-use of random sampling might have given rise to sample selection bias and may limit the findings' generalization. Third, our study did not explore the health-promoting behavior of hospitalized patients and different types of NCDs. Future studies should compare the different types of patients with NCDs or should focus on specific group of patients such as heart failure or cancer patients. Fourth, our study did not explore patient's laboratory testing. Future studies should therefore include patient's laboratory testing during hospitalization with specific group of patients on the basis of their medical records such as blood pressure and blood sugar levels. Finally, as our study had a cross-sectional design, it was not possible to identify the temporal relationships between the independent variables and health-promoting behaviors, and to determine cause-effect relationships. Interventional or longitudinal studies are warranted to clarify patients' long-term outcomes. The future research should involve patients with communicable diseases and other settings (eg, nursing homes and communities) to identify how the HPBs of and perspectives in these populations change as the COVID-19 pandemic shifts in scope.

\section{Conclusion}

The current study showed that perceived benefits of and barriers to the adoption of health-promoting behaviors, perceived self-efficacy, and social support are significant predictors of health-promoting behaviors among hospitalized patients with NCDs during the second wave of COVID-19. Such patients' health outcomes can be affected by the current COVID-19 pandemic and by how they appraise this stressful circumstance in their care environments. Our findings are essential and should be used by researchers, healthcare providers, the government, and policymakers to establish effective interventions, guidelines, and policies for promoting health-promoting behaviors to prevent COVID-19 infection and spread particularly among patients with NCDs.

\section{Abbreviations}

COVID-19, coronavirus disease 2019; NCDs, noncommunicable diseases; PBenS, Perceived Benefit; PSES; Perceived Self-Efficacy Scale; PBarS, Perceived Barriers Scale; SSS, Social Support; HPBS, HealthPromoting Behaviors Scale; HPBs, Health-Promoting Behaviors; COPD, Chronic obstructive pulmonary disease; UHC, universal health coverage; BMI, body mass index.

\section{Data Sharing Statement}

The data that has been used is confidential.

\section{Additional Information}

No additional information is available for this paper.

\section{Acknowledgment}

We would like to thank the participants in our work for their valuable data, the reviewers for their helpful comments and suggestions to improve our study.

\section{Funding}

There is no funding to report.

\section{Disclosure}

The authors declare no conflicts of interest for this work.

\section{References}

1. Suksatan W, Choompunuch B, Koontalay A, Posai V, Abusafia AH. Predictors of health behaviors among undergraduate students during the COVID-19 pandemic: a cross-sectional predictive study. J Multidiscip Healthc. 2021;14:727-734. doi:10.2147/JMDH.S306718

2. WHO. COVID-19 weekly epidemiological update; data as received by WHO from national authorities; 2021a. Available from: https://www. who.int/docs/default-source/coronaviruse/situation-reports/20210105 weekly_epi_update_21.pdf?sfvrsn=15359201_15\&download=true. Accessed January 3, 2021.

3. Choompunuch B, Suksatan W, Sonsroem J, Kutawan S, In-udom A. Stress, adversity quotient, and health behaviors of undergraduate students in a Thai university during COVID-19 outbreak. Belitung Nursing J. 2021;7(1):1-7. doi:10.33546/bnj.1276

4. Worldometers. COVID-19 Coronavirus pandemic; 2020. Available from: https://www.worldometers.info/coronavirus/. Accessed July 11, 2021.

5. WHO. The impact of the COVID-19 pandemic on noncommunicable disease resources and services: results of a rapid assessment; 2021b. Available from: https://www.who.int/publications/i/item/ 9789240010291. Accessed January 3, 2021.

6. Alshukairi AN, Tolah AM, Dada A, et al. Test-based de-isolation in COVID-19 immunocompromised patients: ct value versus SARS-CoV-2 viral cultures. Int $J$ Infect Dis. 2021;108:112-115. doi:10.1016/j.ijid.2021.05.027

7. Stefan N, Birkenfeld AL, Schulze MB. Global pandemics interconnected - obesity, impaired metabolic health and COVID-19. Nat Rev Endocrinol. 2021;17(3):135-149. doi:10.1038/s41574-020-00462-1 
8. Bhutta ZA, Hauerslev M, Farmer M, Lewis-Watts L. COVID-19 children and non-communicable diseases: translating evidence into action. Arch Dis Child. 2021;106(2):141. doi:10.1136/archdischild2020-319923

9. Bello B, Useh U. COVID-19: are non-communicable diseases risk factors for its severity? Am J Health Promotion. 2021;2:0890117121990518. doi:10.1177/0890117121990518

10. Pan X-F, Yang J, Wen Y, Li N, Chen S, Pan A. Non-communicable diseases during the COVID-19 pandemic and beyond. Engineering. 2021. doi:10.1016/j.eng.2021.02.013

11. Kluge HHP, Wickramasinghe K, Rippin HL, et al. Prevention and control of non-communicable diseases in the COVID-19 response. Lancet. 2020;395(10238):1678-1680. doi:10.1016/S0140-6736(20) 31067-9

12. Bennett JE, Stevens GA, Mathers CD, et al. NCD Countdown 2030: worldwide trends in non-communicable disease mortality and progress towards sustainable development goal target 3.4. Lancet. 2018;392(10152):1072-1088. doi:10.1016/S0140-6736(18)31992-5

13. Suksatan W, Ounprasertsuk J. Health-promoting behaviors and related factors in patients with chronic diseases in a rural community. Sys Rev Pharmacy. 2020;11(10):624-627. doi:10.31838/srp.2020.10.93

14. Chantakeeree C, Sormunen M, Jullamate P, Turunen H. Healthpromoting behaviors among urban and rural older Thai adults with hypertension: a cross-sectional study. Pacific Rim Int $J$ Nursing Res. 2021;25(2):242-254.

15. Mattioli AV, Sciomer S, Cocchi C, Maffei S, Gallina S. Quarantine during COVID-19 outbreak: changes in diet and physical activity increase the risk of cardiovascular disease. Nutrition Metab Cardiovascular Dis. 2020;30(9):1409-1417. doi:10.1016/j. numecd.2020.05.020

16. Barlow P, van Schalkwyk MCI, McKee M, Labonté R, Stuckler D. COVID-19 and the collapse of global trade: building an effective public health response. Lancet Planetary Health. 2021;5(2):e102e107. doi:10.1016/S2542-5196(20)30291-6

17. Bunthan W, Whaikit P, Soysang V, Soynahk C, Akaratanapol P, Kompayak J. Factor influencing to health promotion behavior for Coronavirus disease 2019 (COVID-19) prevention of older adults. J Police Nurses. 2020;12(2):323-337.

18. Cohen J. Statistical Power Analysis for the Behavioral Sciences. Academic press; 2013.

19. Faul F, Erdfelder E, Buchner A, Lang A-G. Statistical power analyses using G*Power 3.1: tests for correlation and regression analyses. Behav Res Methods. 2009;41(4):1149-1160. doi:10.3758/ BRM.41.4.1149

20. Malkanthie S, Shin SY. Convergence relationships among nutrition knowledge, health beliefs, self-efficacy, and diet management behaviors in persons with hypertension in Sri Lanka. $J$ Digital Convergence. 2017;15(8):235-245. doi:10.14400/JDC.2017.15.8.235

21. Bunplaeng N. Factors Related to Health-Promoting Behaviors of General Hospital Staff, Phang Nga Province. Chon Buri: Burapha University; 2009.
22. Suksatan W. Factors influencing health-promoting behaviors among people at risk of hypertension in a rural community, Ubon Ratchathani Province. Dis Control Jo. 2019;1:45. doi:10.14456/ dcj.2019.12

23. Seeherunwong A, Suwonnaroop N. An analysis of validity and reliability of the health-promoting lifestyle profile-II in Thai version. Thai J Nursing Council. 2004;19(4):44-53.

24. House JS, Wells JA, Landerman LR, McMichael AJ, Kaplan BH. Occupational stress and health among factory workers. $J$ Health Soc Behav. 1979;20(2):139-160. doi:10.2307/2136435

25. Yoowattana J, Toonsiri C, Homsin P. Factors predicting self-care among elderly with chronic disease in Chaibadan District, Lopburi Province. J Faculty Nursing Burapha Univ. 2017;25(2):69-81.

26. Khami L, Motalebi S, Mohammadi F, Momeni M, Shahrokhi A. Can social support predict health-promoting behaviors among community-dwelling older adults? Soc Health Behavior. 2020;3 (1):22-26. doi: $10.4103 / \mathrm{shb}$.Shb 5019

27. Giena VP, Thongpat S, Nitirat P. Predictors of health-promoting behaviour among older adults with hypertension in Indonesia. Int $J \quad$ Nursing $\quad$ Sci. $\quad 2018 ; 5(2): 201-205 . \quad$ doi:10.1016/j. ijnss.2018.04.002

28. Rasamejam P, Akaratanapol P, Limteerayos P, Khungtumneam K. Factors predicting health promoting behaviors among Thai Muslim with hypertension. J Nursing Siam Univ. 2018;19(37):56-68.

29. Pender NJ, Murdaugh CL, Parsons MA. Health Promotion in Nursing Practice. Pearson Prentice Hall, Upper Saddle River; 2006.

30. Bandura A. Self-efficacy mechanism in human agency. Am Psychologist. 1982;37(2):122-147. doi:10.1037/0003-066X.37.2.122

31. Lim EJ, Noh JH, Kim EY. A Study of factors affecting health-promoting behaviors to young-elderly adults in urban and rural communities. Int $J$ Bio Sci Bio-Tech. 2015;7(5):367-374. doi:10.14257/ijbsbt.2015.7.5.36

32. Oluma A, Abadiga M, Mosisa G, Fekadu G, Turi E. Perceived self-efficacy and associated factors among adult patients with type 2 diabetes mellitus at public hospitals of Western Ethiopia, 2020. Patient Prefer Adherence. 2020;14:1689-1698. doi:10.2147/PPA. S275887

33. Khairy S, Aslan A, Samara AM, Mousa I, Alkaiyat AS, Zyoud S. Factors associated with self-efficacy in patients with hypertension: a cross-sectional study from Palestine. J Health Popul Nutr. 2021;40 (1):1. doi:10.1186/s41043-021-00225-2

34. Chen AMH, Yehle KS, Plake KS, et al. The role of health literacy, depression, disease knowledge, and self-efficacy in self-care among adults with heart failure: an updated model. Heart Lung. 2020;49 (6):702-708. doi:10.1016/j.hrtlng.2020.08.004

35. Kar S, Zengin N. The relation between self-efficacy in patients with chronic obstructive pulmonary disease and caregiver burden. Scand J Caring Sci. 2020;34(3):754-761. doi:10.1111/scs.12780
Journal of Multidisciplinary Healthcare

\section{Publish your work in this journal}

The Journal of Multidisciplinary Healthcare is an international, peerreviewed open-access journal that aims to represent and publish research in healthcare areas delivered by practitioners of different disciplines. This includes studies and reviews conducted by multidisciplinary teams as well as research which evaluates the results or conduct of such teams or healthcare processes in general. The journal covers a very wide range of areas and welcomes submissions from practitioners at all levels, from all over the world. The manuscript management system is completely online and includes a very quick and fair peer-review system. Visit http://www.dovepress.com/testimonials. php to read real quotes from published authors. 